\title{
Antigen size influences the type of glomerular pathology in chronic serum sickness
}

\author{
P. C. W. Hogendoorn ${ }^{1}$, E. B. L. van Dorst ${ }^{1}$, S. H. van der Burg ${ }^{1}$, J. A. Bruijn, M. R. Daha ${ }^{2}$, \\ $\mathrm{Ph}$. J. Hoedemaeker ${ }^{1}$ and G.-J. Fleuren ${ }^{1}$ \\ Departments of ${ }^{1}$ Pathology and ${ }^{2}$ Nephrology, University of Leiden, The Netherlands
}

\begin{abstract}
Chronic serum sickness was induced in four groups of Wistar rats by immunization with BSA, cationized BSA (cBSA), human IgG (HuIgG), or human IgM (HuIgM), followed by repeated intraperitoneal (i.p.) injection of the antigen used, to study the effect of the characteristics of an antigen on renal immunopathology. Renal tissue sampled 2, 4, 7, and 9 weeks after the start of the i.p. injections was examined by light-, immunofluorescence-, and electronmicroscopy. Proteinuria was measured in urine collected over $24 \mathrm{~h}$. All animals given BSA, cBSA, or HulgG developed progressive renal disease characterized by initial deposition of antigen and rat Ig in the mesangium of rats given BSA or HulgG, and minimal amounts in those given cBSA, followed by the appearance in the first instance of subendothelial deposits in the animals receiving BSA or HulgG, and later subepithelial deposits in those given BSA, cBSA, or HulgG. The appearance of immunoglobulin deposits along the glomerular capillary wall was associated with the onset of massive proteinuria reaching average levels of $450 \mathrm{mg} / 24 \mathrm{~h}$ for rats given BSA or cBSA, and $500 \mathrm{mg} / 24 \mathrm{~h}$ for those given HulgG. Animals injected with HulgM showed only mesangial deposits of human IgM and rat Ig without the development of proteinuria. Under light-microscopy, rats given BSA, cBSA, or HulgM showed minimal abnormalities, whereas those receiving HulgG showed transient but severe influx of granulocytes in glomeruli with the development of diffuse proliferative glomerulonephritis in association with a long-lasting phase characterized by subendothelially localized immune aggregates. No differences in the degree or type of the immune response were found either as measured by ELISA or double radial immunodiffusion. We conclude that the type of glomerular immunopathology during chronic serum sickness is partially dependent on the size of the antigen used for induction of the disease.
\end{abstract}

Correspondence and offprinrequests to: Pancras C. W. Hogendoorn MD PhD. Department of Pathology. University of Leiden, P.O. Box 9603. 2300 RC Leiden, The Netherlands.
Key words: chronic serum sickness; antigen size; ELBA

\section{Introduction}

During the last few decades, research using animal models has yielded considerable information about the pathogenic mechanisms underlying immunologically mediated glomerulonephritis [1]. Originally, a pathogenic role was established for antibodies directed to antigens of the glomerular capillary wall (GCW) [2], which gave rise to a linear binding of antibodies along the GCW. Not long afterward, Germuth [3] demonstrated an additional role for circulating immune complexes in experimental serum sickness glomerulonephritis, in this case leading to a granular binding of IgG along the GCW. New studies began to show that a pathogenic role played by antibodies directed against glomerular intrinsic or planted antigens can induce either linear or granular binding of $\operatorname{IgG}$ along the GCW [4-6]. Models have recently been described in which the binding pattern of antibodies to the glomerulus can change from linear to granular in the course of the disease. It became clear that the character of the antigen involved was not only an important denominator of the binding pattern of the antibody in the glomerulus, but can also determine the morphology of the glomerulonephritis it causes [7]. It was in this context that we became interested in chronic serum sickness as a model for human immune-mediated kidney disease induced in rats by immunization with and subsequent repetitive intraperitoneal injections of a species-foreign protein $[8,9]$. In this model the binding pattern of antibodies to the glomerular planted antigen changes from a mesangial to a membranous pattern during the course of the disease. This change has been attributed to the height of the immune response [10], the avidity [11-13] or precipitability of the antibodies produced [13], or the characteristics of the antigen(s) involved, e.g. immunogenicity and/or electrical charge [14].

In the present study we attempted to assess the role played by the molecular weight of the antigen in 
relation to the type of glomerulonephritis. Chronic serum sickness was induced with three antigens differing in molecular weight: native BSA (mol wt $66 \mathrm{kDa}$ ), human IgG (HuIgG) (mo! wt $155 \mathrm{kDa}$ ), and human IgM (HuIgM) (mol wt $900 \mathrm{kDa})$. As an additional control, BSA with a neutral pl $(7.4$; cBSA) was used to exclude the role of electrical charge.

\section{Subjects and methods}

\section{Animals}

Fifty 10 -week-old female inbred Wistar rats weighing about $250 \mathrm{~g}$ each were used in this study.

\section{Antigens}

Crystalline BSA (Sigma Chemical Company, St Louis, Mo., USA) was used as native BSA and as a substrate for the preparation of charge-modified BSA, neutral at physiological $\mathrm{pH}$. Crystalline HulgG was obtained from the CLB, Amsterdam, The Netherlands. HuIgM was purified from $200 \mathrm{ml}$ of human myeloma serum which was first heated $\left(30 \mathrm{~min} ; 56^{\circ} \mathrm{C}\right)$ to destroy complement activity. After this the serum was centrifuged $(10 \mathrm{~min} ; 10000 \mathrm{~g}$ ) and the supernatant was dialysed against $0.01 \mathrm{M}$ sodium acetate buffer, $\mathrm{pH} 6.0$; conductivity $1 \mathrm{mS}$ at $4^{\circ} \mathrm{C}$. The resulting pellet was collected by centrifugation at $4^{\circ} \mathrm{C}$ for $15 \mathrm{~min}$ at $20000 \mathrm{~g}$, dissolved in $1 \mathrm{M} \mathrm{NaCl}$ containing $2 \mathrm{mM}$ EDTA and subjected to gel filtration on a Sephacryl S-500 (Pharmacia, Woerden, The Netherlands). The fractions containing IgM were detected by ELISA using a monoclonal antibody (HB 57, American Tissue Type Culture Collector, Rockville, Mo), pooled. concentrated to $20 \mathrm{mg} / \mathrm{ml}$, and dialysed against phosphatebuffered saline $\mathrm{pH} 7.4$ (PBS). The isoelectric point of the commercial BSA was adjusted to pl 7.4 by cationization induced by carbodiimide activation (EDC, Sigma Chemical Company) of carboxyl groups and substitution by N,Ndimethyl-1,3-propanediamine (Merck, Schuchardt, BRD) according to Danon el at. [15]. After that, the average isoelectric point of BSA, both charge modified and native, and $\mathrm{HulgG}$ was measured in thin layers of polyacrylamide gel containing ampholytes with a $\mathrm{pH}$ range of 3.5-9.5, using an LKB flat-bed isoelectrofocusing unit (LKB Instruments Inc., Bromma. Sweden). The isoelectric point of HulgM was assessed by chromatofocusing. The final molecular weight of the four antigens used was assessed by gel chromatography on a Sephacryl S-300 column (Pharmacia Fine Chemicals Inc., Uppsala, Sweden).

\section{Induction of chronic serum sickness}

Chronic serum sickness was induced as described elsewhere [8]. In short, groups of 10 rats each were immunized intracutaneously with $1.5 \mathrm{mg}$ native BSA (group I), cBSA (group II), HulgG (group III), or HulgM (group IV), all diluted in $0.15 \mathrm{ml}$ PBS and emulsified with $0.15 \mathrm{ml}$ complete Freund's adjuvant (Difco Laboratories, Detroit, Mich., USA). Fortytwo days later the animals received an intracutaneous booster injection consisting of either $1.5 \mathrm{mg} \mathrm{BSA}, \mathrm{cBSA}$, HulgG, or HulgM diluted in $0.15 \mathrm{ml}$ PBS, emulsified with $0.15 \mathrm{ml}$ incomplete Freund's adjuvant. Starting on day 56, 10 i.p. injections of either $3 \mathrm{mg}$ BSA, cBSA, HulgM, or $6 \mathrm{mg}$ HulgG diluted in $1 \mathrm{ml}$ PBS were given over a period of 14 days, followed by three i.p. injections of the same solution weekly over a period of up to 9 weeks. Ten control rats received injections of the same vehicle but without antigen (group V). This regimen was chosen because pilot experiments had shown this to lead to immune complex type glomerular disease at comparable levels and type of antigen-specific antibodies. Administration of the antigens was stopped when proteinuria of higher than $500 \mathrm{mg} / 24 \mathrm{~h}$ was reached. All animals were killed on day 150 .

\section{Morphological studies}

Small tissue specimens $\left(0.3 \mathrm{~mm}^{3}\right)$ for light-, immunofluorescence-, and electron-microscopy were taken by open biopsy from alternate sides under ether anaesthesia on days 70,84 , 108 , 122, and immediately after death. Tissue for light- and electron-microscopy was processed as detailed previously $[16,17]$. The morphological changes were evaluated independently by two microscopists. A portion of the kidney tissue was snap-frozen in $\mathrm{CO}_{2}$ ice-cooled isopentane and stored at $-70^{\circ} \mathrm{C}$ until use. For the immunofluorescence studies, sections were processed as described elsewhere [16]. Use was made of the direct technique with goat-anti-rat IgG, rabbit-anti-rat IgG1, lgG2a, IgG2b, or IgM, as well as goat-anti-human IgG and IgM fiuorescein isothiocyanate (FITC) conjugated immunoglobulins (Nordic Immunology, Tilburg, The Netherlands) or rabbit-anti-rat complement component 3 FITC-conjugated immunoglobulins, prepared as already described [18]. Immunofluorescence staining intensity was scored semiquantitatively $(-$ to ++$)$.

\section{Measurement of circulating antigen-specific antibodies}

For the measurement of circulating antibodies to BSA, cBSA, HulgG, or HulgM, blood samples were collected by orbital plexus bleeding, before immunization, on days 14, 28, 42, $56,63,70,77,84$, and after that once a month until the end of the experiments. Antibody levels were measured with an ELISA using polyvinylchloride ELISA plates (Titertek, Flow Laboratories, Zwanenburg, The Netherlands) coated with either BSA, or HulgG, or HulgM (1 $\mu \mathrm{g} /$ well) diluted in $0.1 \mathrm{M}$ sodium carbonate buffer $(\mathrm{pH}$ 7.6) and processed as described previously [8]

For determination of the subclass of the induced antibodies the studies were performed with either rabbit-anti-rat polyvalent IG, IgG1, IgG2a, IgG2b, IgG2c, or IgM (Nordic Immunology) in the second incubation step. Titres of precipitable antibodies directed against the antigens used were assessed with Mancini's double diffusion technique.

\section{Quantitative measurement of protein excretion in the urine}

Twenty-four-hour urine was collected in metabolic cages at three time-intervals before the experiments were started, and on days $43,57,71$, and after that weekly until the end of the observation period as described previously [16].

\section{Statistical analysis}

Student's / test combined with the Scheffe procedure was used to determine the level of significance of differences between paired data. For the comparison of values of all groups, variance analysis was used. $P$ values lower than 0.05 were considered significant. All results are expressed as mean \pm standard deviation. 


\section{Results}

\section{Experimental antigens}

The molecular weight of the antigens used is given together with their isoelectric point in Table 1.

\section{Morphological studies}

Immunofluorescence microscopy. Both native BSA(group I) and HuIgG-induced (group III) chronic serum sickness were associated with deposition of antigen and rat $\mathrm{Ig}$ in the mesangium from day 70 onward (Figure la). This was followed in due course by the appearance of granular deposits along the glomerular capillary wall, observed first for rats with BSA-induced serum sickness, but from day 84 onward coarse granular deposits were also seen in rats given HuIgG (Figure 1b). Group II showed a mesangial deposition pattern from day 70 on in about $40 \%$ of the animals. On day 84 a shift toward a capillary localization became prominent, the process bringing about an intensely stained fine granular pattern by day 108. HuIgM-induced (group IV) chronic serum sickness showed mesangial deposits of HuIgM and rat IgG from days 84 and 108 respectively (Figure 2), but a change to a localization along the glomerular capillary wall did not occur. In all groups the antibodies deposited were predominantly of the IgGl and $\lg G 2$ a class, to a lesser extent IgM, and there were only minimal amounts $\operatorname{IgG} 2 \mathrm{~b}$. The course of the fluorescence patterns is summarized in Table 2.

Electron-microscopy. The granular staining of the glomerular capillary wall reflected subendothelial deposits in the early stage, and later subepithelial electron-dense deposits, in groups I and HI. Subendothelial immune deposits persisted longer in group III than in group I (Figure 3). cBSA led only to localization of electron-dense deposits in the subepithelial space, mainly in the slit-pores. HulgM-induced chronic serum sickness (group IV) exclusively showed a mesangial localization of electron-dense material. The results of the electron-microscopical findings are summarized in Table 3.

Histopathology. The most prominent differences between the experimental groups were seen in the degree of margination of polymorphonuclear granulocytes (PMNs) and monocytes, up to 12 per glomerulus

Table L Characteristics of the antigens used for the induction of chronic serum sickness*

\begin{tabular}{lcl}
\hline & $\begin{array}{l}\text { Molecular weight } \\
(\mathrm{kDa})\end{array}$ & $\begin{array}{l}\text { Isoelectric point } \\
(\mathrm{pl})\end{array}$ \\
\hline BSA & 66 & 4.2 \\
cBSA & 66 & 7.5 \\
Human IgG & 155 & $7.5-8.0$ \\
Human IgM & 900 & $6.5-7.5$ \\
\hline
\end{tabular}

* Molecular weight and isoelectric point of BSA, cBSA, Human $\mathrm{IgG}$, and Human IgM. The isoelectric point of the latter three is within the same range.
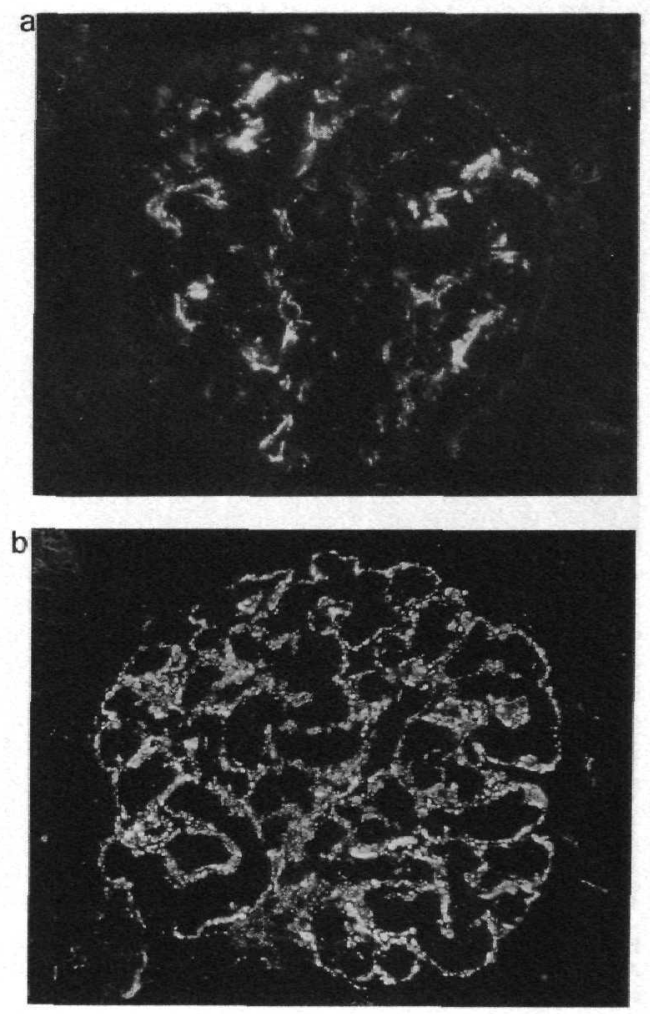

Fig. 1. Immunofluorescence micrographs of a glomerulus from a rat with HuIgG-induced serum sickness glomerulopathy. (a) Changes in the early phase of the disease (day 70), Deposits of rat IgG are confined to the mesangial area. (b) Changes in the membranous phase of the disease (day 108). Granular deposits of rat IgG are present along the glomerular capillary wall. (Both a and b x 630)

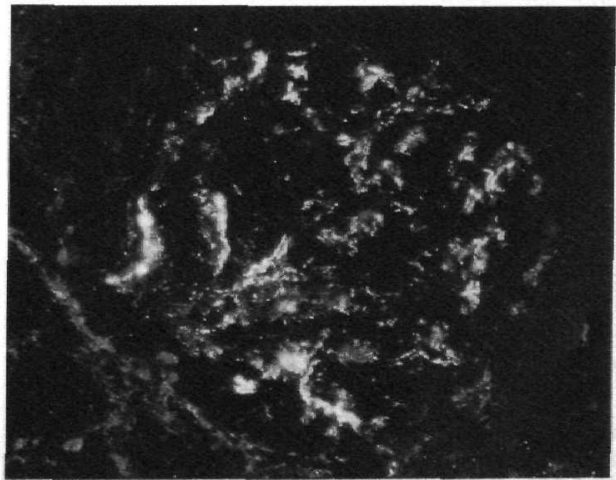

Fig. 2. Immunofluorescence micrograph of a glomerulus from a rat with HulgM-induced serum sickness glomerulopathy, stained with anti-HuIgM-FITC. Deposits of rat immunoglobulins can be seen in the mesangial areas. $(\times 630)$ 


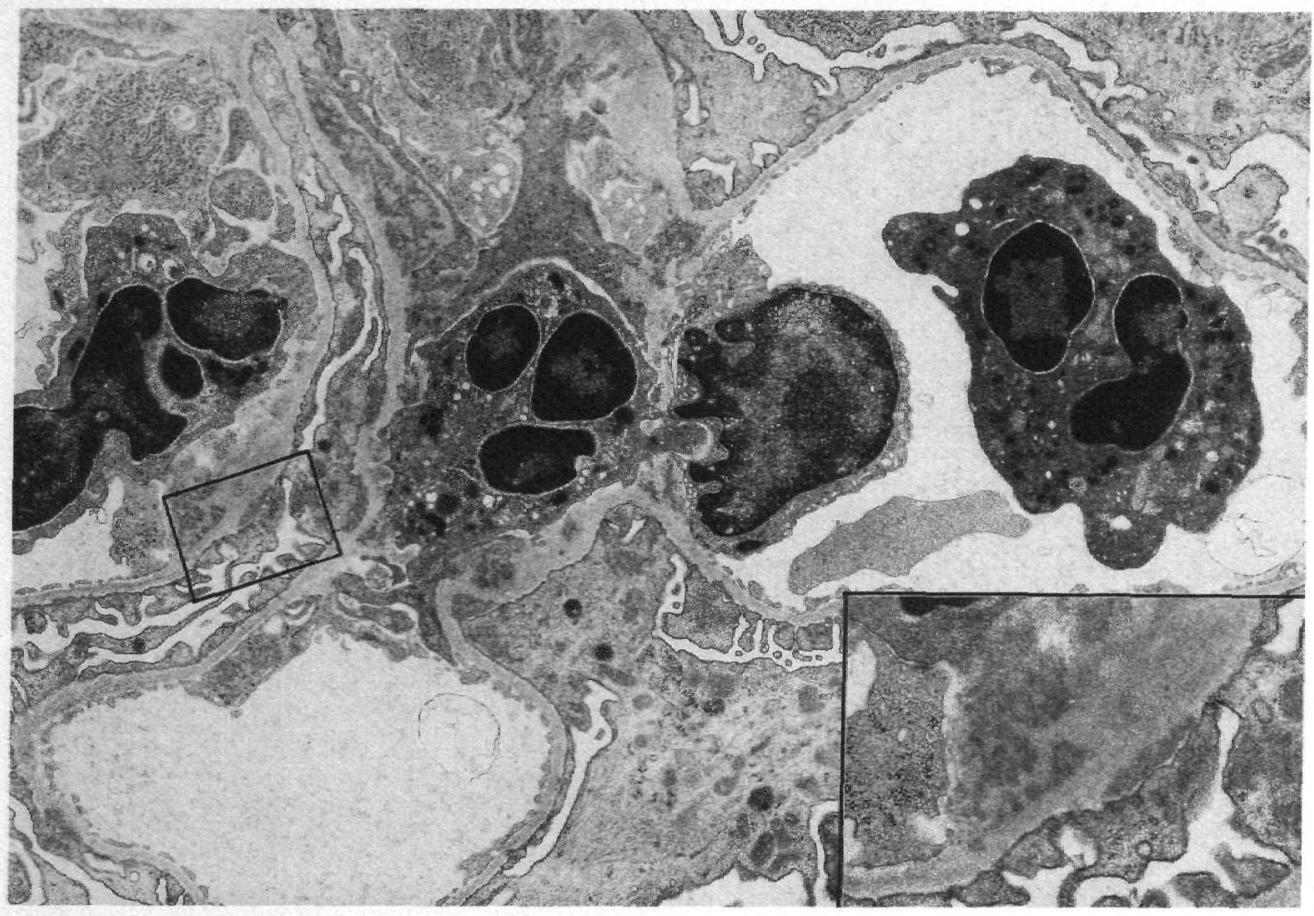

Fig. 3. Electron-micrograph showing the immunological damage to the GBM 100 days after HuIgG-induced experimental serum sickness. At this time, electron-dense material is localized in both the subendothelial and the subepithelial areas of the GBM and polymorphonuclear cells are conspicuous. \{ x 8500 and x 20000\}

Table 2. Combined results of immunofluorescence and electronmicroscopy

\begin{tabular}{|c|c|c|c|c|c|c|}
\hline \multirow[t]{2}{*}{ Group } & \multirow[t]{2}{*}{ Day } & \multicolumn{2}{|c|}{ Mesangium } & \multicolumn{3}{|c|}{ Glomerular capillary wall } \\
\hline & & IgG & $\mathrm{C} 3$ & Subendothelial & Subepithelial & $\mathrm{C} 3$ \\
\hline \multirow[t]{5}{*}{ I } & 70 & ++ & + & \pm & - & - \\
\hline & 84 & + & + & \pm & ++ & \pm \\
\hline & 108 & \pm & - & + & ++ & + \\
\hline & 122 & - & - & - & ++ & ++ \\
\hline & 150 & - & - & - & ++ & + \\
\hline \multirow[t]{5}{*}{ I } & 70 & \pm & \pm & - & - & - \\
\hline & 84 & \pm & \pm & - & \pm & - \\
\hline & 108 & \pm & - & - & + & + \\
\hline & 122 & & & es & +4 & $\rightarrow$ \\
\hline & 150 & - & - & - & ++ & ++ \\
\hline \multirow[t]{5}{*}{ III } & 70 & ++ & + & & - & - \\
\hline & 84 & + & + & \pm & & \pm \\
\hline & 108 & \pm & & ++ & ++ & ++ \\
\hline & 122 & - & - & \pm & ++ & ++ \\
\hline & 150 & - & - & - & ++ & \pm \\
\hline \multirow[t]{5}{*}{ IV } & 70 & + & + & - & - & - \\
\hline & 84 & ++ & + & & - & - \\
\hline & 108 & + & + & - & - & - \\
\hline & 122 & + & - & & - & - \\
\hline & 150 & \pm & - & - & - & - \\
\hline
\end{tabular}

Group I, BSA-induced serum sickness; group II, cBSA-induced serum sickness: group III, HuIgG-induced serum sickness; group IV, HulgM-induced serum sickness. in rats receiving HuIgG, which was detectable between days 84 and 108 (Figure 4). An influx of granulocytes also occurred briefly in glomeruli of rats given native BSA, but was of a much lower level. In rats given

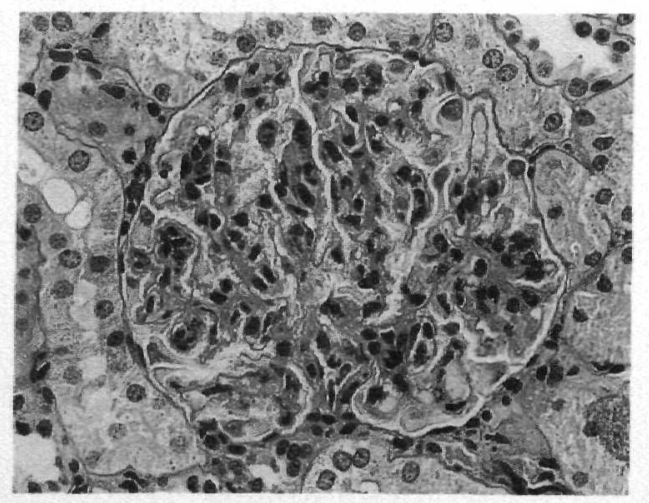

Fig. 4. Light-micrograph of a glomerulus from a rat suffering from HuIgG-induced serum sickness glomerulopathy, showing marked influx and margination of granulocytes. (PAS, x 400) 
cBSA there was no glomerular influx of PMNs either in the mesangial area or marginated along the glomerular capillary wall. Furthermore, at the end of the experiment glomeruli of rats in group I showed significant glomerulosclerosis, thus confirming an earlier finding [8].

Severe glomerulosclerosis exceeding that observed in group I with respect to number of involved glomeruli and extent of involvement was seen at the end of the observation period in rats with HuIgG-induced serum sickness. Throughout the observation period no significant glomerular abnormalities were observed in the kidneys of rats receiving $\mathrm{HuIgM}$, whereas group II showed only minimal mesangial abnormalities. Finally, the interstitial area of kidney biopsy specimens of all the animals showed peritubular tymphocytic infiltrates, thus confirming earlier reports [19]. The results obtained with light-microscopy are given in Table 3.

\section{Measurement ofcirculating antigen-specific antibodies}

The ELISA showed a peak value of rat IgM antibodies on day 14 , followed by a slow decrease in time, but with a sharp reduction on day 56 in groups I, II, and III. Antigen-specific $\operatorname{IgG} 2 b$ and $\operatorname{IgG} 2 c$ concentrations were low in all groups, the greatest concentrations occurring around day 42 , followed by a decrease after day 56 in groups I, II, and III. Titres of IgG2a and IgGl were high in all groups, with an initial a peak on day 14 for both classes, rising to the highest titres of antigen-specific IgGl on day 56 in groups I and II and on day 70 in groups III and IV. After day 63 antigenspecific IgG2a declined sharply in groups I, II, and III, as did the IgGl in groups I and II.

IgGl in group III showed this reduction after day 77. Levels of $\operatorname{IgG} 2 \mathrm{a}$ and $\mathrm{IgGl}$ against HulgM decreased slowly after day 70 but large amounts were still detectable in the circulation at the end of the experiment. There were no significant differencesin the amounts of specific antibodies between all groups before the sudden decline of the antibody titres in groups I, II, and III, coinciding with the accumulation of deposits along the glomerular capillary wall in these groups as well as with the development of proteinuria.

Table 3. Morphological changes at the light-microscopic ieve!

\begin{tabular}{|c|c|c|c|c|}
\hline Group & Day 70 & Day 84 & Day 108 & Day 150 \\
\hline & $a, b$ & $a, b, c(1-2)$ & \multirow{4}{*}{$\begin{array}{l}\text { a,e,f } \\
\text { f } \\
\text { a,b,c, }(<12) \\
\text { d }(+), e, f \\
\text { f }\end{array}$} & $d(+\cdot+), e, f$ \\
\hline & $a, b$ & & & \\
\hline IIII & $a, b$ & $a, b, c \quad(4-6)$ & & $\mathrm{d}(+++), \mathrm{e}, \mathrm{f}$ \\
\hline IV & $\mathrm{g}$ & $\mathrm{g}$ & & $\mathrm{f}$ \\
\hline
\end{tabular}

a. Hypercellularity; b, mesangial expansion; c. margination of granulocytes, number of cells per glomeruius in parentheses; $d$, progressive glomerulosclerosis $(+,++,+++)$; e, protein cast and degradation of tubular epithelium; $f$, interstitial peritubular lymphocytic infiltrates; g, minimal light-microscopic changes. Group I, BSA-induced serum sickness; group IT, cBSA-induced serum sickness; group III. HulgG induced serum sickness; group IV, HuIgM-induced serum sickness.
Precipitating antibody titres directed against BSA or $\mathrm{HulgG}$, as measured by double diffusion, showed high titres in groups I, II, and HI. Group IV tended to have a slightly higher titre of precipitable antibodies, but this difference was not statistically significant. A week before the onset of pathological proteinuria in groups I, II, and III the level of circulating precipitating antibodies decreased by about $60 \%$, thus confirming the findings of Noble et al. in BSA-induced chronic serum sickness [10]. The sera of the animals in group IV did not show a significant reduclion in the precipitable antibody titres in the course of the experiments.

\section{Quantitative measurement of protein excretion in the urine}

The course of the mean values of protein excretion in the urine is shown in Figure 5. Animals in group I showed proteinuria from day 63 onward, reaching a peak of $450 \mathrm{mg} / 24 \mathrm{~h}$ around day 100 , as seen earlier [8]. cBSA-induced glomerulopathy gave rise to proteinuria from day 91 onward, which increased up to average levels of $450 \mathrm{mg} / 24 \mathrm{~h}$. Group III showed proteinuria from day 84 onward, with peak levels of on average $500 \mathrm{mg} / 24 \mathrm{~h}$ on days $105-130$. Throughout the period studied, rats with HulgM-induced chronic serum sickness showed no significant proteinuria relative to the control rats, the physiological protein excretion of the control animals being lower than $15 \mathrm{mg} / 24 \mathrm{~h}$.

\section{Discussion}

The study reported here has shown that the characteristics of a planted antigen, especially its size, exert an influence on the type of immunopathological glomerular injury that evolves when an immune reaction is launched against that antigen. The three principal

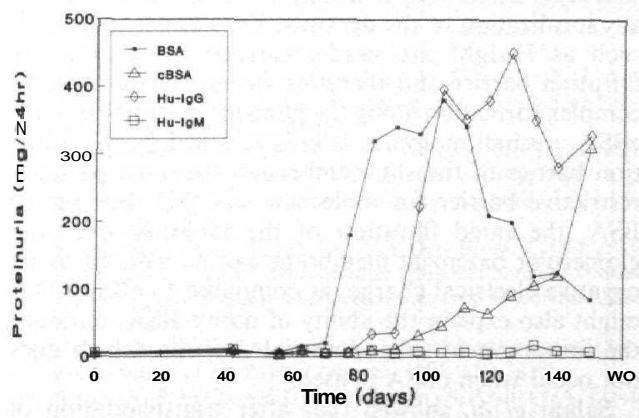

Fig. 5. Course of the mean values of protein excretion in the urine of rats after the induction of serum sickness, calculated for groups given BSA (I), cBSA (II), Hu-IgG (HI), or HulgM (IV). Serum sickness glomerulopathy induced by native BSA, cBSA, or HulgG was accompanied by the development of proteinuria. Induction of serum sickness glomerulopathy by repeated injection of HulgM did not lead to the development of significant proteinuria. 
antigens used, i.e. cBSA, HuIgG, and HuIgM, differed in molecular weight in a range between $66 \mathrm{kDa}$ and $900 \mathrm{kDa}$, but had comparable isoelectric points. Depending upon their size, the antigens induced either a mesangial and subepithelial (cBSA, group II) or a mesangial, subendothelial, and subepithelial (HulgG, group III), or a strictly mesangial localization of immune complexes (HulgM, group IV). Native BSA, an antigen with an anionic nature, was used for studies performed to find out whether the strict mesangial localization in group IV (HulgM), induced by an antigen with a slightly less cationic isoelectric point compared to cBSA and HulgG, was influenced by electrical charge. Native BSA (group I, pl 4.2) was in fact quite capable of inducing immune-complex formation along the glomerular capillary wall, which excludes a charge-dependent inability of HulgM (pl 6.5) to localize along the glomerular capillary wall.

In chronic serum sickness, the occurrence of subepithelially localized immune complexes was shown to result from in situ formation after the combination of antigen and antibody travelling separately across the glomerular basement membrane [5]. As shown by Rennke and Venkatachalam, the glomerular capillary wall acts by selectively filtering molecules according to their size, configuration, and electrical charge [20]. Likewise, the constituents of the immune aggregates localized along the glomerular capillary wall in a planted antigen model may have passed the GBM under the same restrictions as those imposed by the filtration properties of the glomerular capillary wall. Molecules with a small effective radius can pass the glomerular filter barrier easily, retention occurring increasingly effectively with enlarging size of the molecules. Molecules with a large diameter may only reach the subepithelial region in small numbers or not at all, since passage through the glomerular capillary wall is hampered by the relatively small pore size particularly of the lamina densa. This explains why in our experiments the injection of relatively large molecules such as HulgG led initially to a predominantly subendothelially localization of the deposits. Even larger molecules such as HuIgM are hardly capable of passing the filtration barrier and therefore do not incite immune complex formation along the glomerular capillary wall. cBSA. a small molecule, is only retained by the filtration barrier of the slit membranes, the most passagerestrictive barrier for molecular size [21]. For native BSA, the rated filtration of the molecule over the glomerular basement membrane can be reduced by its negative electrical charge, as compared to cBSA. This might also explain the ability of native BSA to induce the formation of subendothelial deposits, which does not occur when cBSA is used.

Salant et al. showed that after transplantation of kidneys of rats previously injected with either heterologous anti-GBM or anti-FxlA antibodies, which before transplantation gave rise to a linear GBM or subepithelial binding of the antibodies respectively, the site of binding of heterologous antibodies directed against renal autoantigens had a direct influence on the mediation and morphological expression of renal immunopathology [22]. Studies in other autoimmune models have also shown an influence of the localization of the target molecule (or epitope) on renal immunopathology [7,17].

Moreover, studies by Fries et al. [23], who used a planted antigen model, showed that the disease processes that ensued from immune-complex formation at opposite sites of the GBM differed remarkably in their functional and structural appearance. In our model employing planted antigens, the type of the evolved glomerulonephritis also depended upon the glomerular distribution of the antigen used, because the localization of the glomerular immune aggregates influences chemotactic activity. The glomerular influx of PMNs and monocytes was distinct in group III and to a lesser extent in group I, and therefore seemed to be related to the presence of subendothelial immune complexes. Indeed it has been suggested that these cells are attracted by the presence of subendothelial immune complexes, and bind to them via their Fc-receptor [24]. In various forms of glomerulonephritis these cells are known to have a tissue-damaging effect and may modulate proteinuria [25-27]. In particular, monocytes have been postulated to play a pathogenic role in certain forms of serum sickness glomerulonephritis [27]. In patients, intraglomerular monocyte accumulation occurs [28] mainly in types of glomerulonephritis characterized by the presence of subendothelial immune complexes [29]. Cationic proteins released from PMNs and platelets may interact with the anionic structures of the GBM [30]. After this chargedependent interaction the deposition of antibodies in the glomerular capillary wall may be enhanced, as has been shown with the cationic tracer polyethyleneimine in the Heymann model as well as in passive serum sickness [16,31]. PMNs and monocytes may have contributed by these mechanisms to the development of proteinuria in group III, and might also have mediated the occurrence of focal and segmental sclerosis seen on a large scale in this group and to a lesser degree in group I. Thus, one of the ways by which the characteristics of a planted antigen can determine the glomerular damage is by influencing the localization of immune complexes, which in turn affects factors such as chemotaxis.

Lupus nephritis, a disease for which chronic serum sickness has been proposed as an animal model, exhibits a range of morphological lesions as classified by the WHO from minimal changes up to proliferative types seen in the majority of the patients. The WHO categories correspond with circumscript immunofluorescence and electron-microscopical findings. In SLE a multiplicity of immune reactions to cellular and serum antigens develops, but a causative antibody specificity or antigen has not been identified.

Recently, Schmiedeke et al. showed that histones, a family of proteins with a strong positive charge with a wide range of molecular weights, have a high affinity for the glomerular basement membrane, and postulated that they are planted autoantigens active in the patho- 
genesis of lupus nephritis [32]. Antigens with different molecular weights may be responsible for the different morphological presentations of the glomerular pathology. Planted autoantigens with a high molecular weight might be responsible for the mesangial immune deposits and minimal abnormalities found lightmicroscopically, for example those seen in class II lupus nephritis. Proliferative types of glomerulonephritis with subendothelial immune deposits - WHO class III and IV - could in turn be due to intermediate high-molecular-weight antigens, whereas in the membranous form - WHO class V-an antigen of relative low molecular weight could be responsible.

Coinciding with the development of proteinuria, accompanied in time by the appearance of subepithelial electron-dense deposits in groups I, II, and III, there was a steep decline in the amount of circulating antibodies of precipitating quality, as described elsewhere [33,34]. Interestingly, in patients with active SLE the clinical manifestations of the disease have been reported to coincide with a sharp decline in antidsDNA antibodies as well [35]. Indeed, in our experiments group IV, which did not show a glomerular capillary wall localization of immune aggregates or pathological proteinuria in the course of the disease, did not show this decline of the antibody titre either. The level and type of the antigen-specific immune response were comparable in all groups, and no differences were observed in the precipitability of the evoked antibodies. All this makes an influence of differences in the antibody response evoked by the antigens in question on the immunopathological features unlikely.

An important feature of two of the antigens used, i.e. HuIgG and HuIgM, is that they have an antibodylike structure. In general, during glomerulonephritis immune complexes might be present within immune deposits formed by specific antigenic determinants on the IgG molecules and by anti-idiotype antibodies [36]. In this way, various antibodies with different size and charge, acting as planted antigens, might constitute a target for an anti-idiotypic immune response. In man, Ig-anti-Ig complexes of the rheumatoid type have been suggested as of nephritogenic importance in various types of glomerular immunopathology, including lupus nephritis, essential cryoglobulinaemia-associatednephritis, and poststreptococcal glomerulonephritis. Because of their molecular size, IgM-rheumatoid factors could be expected to localize only in the mesangial area, whereas IgG-rheumatoid factors might occur not only in the mesangium but also in a subendothelial localization and, later in the course of the disease, even subepithelially.

The characteristics of a planted antigen, including its size, may partially account for the variety of clinical and histopathological manifestations of planted antigen-induced glomerulonephritis.

Acknowledgements. This work was supported by a grant from the Dutch Kidney Foundation. The authors are indebted to Dr E. de Heer for his constructive criticism, and to L.J.C.M. v.d. Broek, F.A. Prins, and J. v.d. Ploeg for technical assistance.

\section{References}

1. Hoedemaeker $\mathrm{PhJ}$, Weening JJ. Relevance of experimental models for human nephropathology. Kidney Int 1989; 35: 1015

2. Masugi M, Sato Y. Ueber die allergische gewebsreaktion der niere. Zugleich ein experimentelle beitrag zur pathogenese der diffusen glomerulonephritis und der Periarteritis Nodosa. Virchows Arch (Palhol Anal) 1934; 293: 615

3. Germuth FG. A comparative histologic and immunologic study in rabbits of induced hypersensitivity of the serum sickness type. J Exp Med 1953; 97:257

4. Couser WG, Steinmuller DR, Stilmant MM, Salant DJ, Lowenstein LM. Experimental glomerulonephritis in the isolated perfused raS kidney. J Clin Invest 1978; 62: 1275

5. Fleuren GJ, Grond J, Hoedemaeker PhJ. In situ formation of subepithelial glomerular immune complexes in passive serum sickness. Kidney Inl 1980; 17: 631

6. Van Damme BJC, Fleuren GJ, Bakker WW, Vernier RL, Hoedemaeker $\mathrm{PhJ}$. Experimental glomerujonephritis in the rat induced by antibodies directed against tubular antigens. V. Fixed glomerular antigens in the pathogenesis of heterologous immune complex glomerulonephritis. Lab Invest 1978; 38: 502

7. Bruijn JA, Hogendoorn PCW, Hoedemaeker PhJ, Fleuren GJ. The extracellular matrix in pathology. A review. J Lab Clin Med 1988; $111: 140$

8. Hogendoorn PCW. Bruijn JA, Gelok EWA, Van Den Broek LJCM. Fleuren GJ, Development of progressive glomerulosclerosis in experimental CSS. Nephrol Dial Transplant 1990; 5: 100

9. Bolton KW, Sturgill BC. Bovine serum albumin chronic serum sickness nephropathy in rats. Br J Exp Palhol 1978; 59: 167

10. Noble B, Steward MW, Vladutiu A, Brentjens JR. Relationship of the quality and quantity of circulating anti-BSA antibodies to the severity of glomerulonephritis in rats with chronic serum sickness. Clin Exp Immunol 1987; 67: 277

11. Germuth FG, Rodriguez E, Lorelle CA, Trump EI, Milano M, O'Wise L. Passive immune complex glomerulonephritis in mice: Models for various lesions found in human disease. 1. High avidity complexes and mesangiopathic glomerulonephritis. Lab Invest 1979; 41: 360

12. Germuth FG, Rodriguez E, Lorelle CA, Trump EI, Milano M, O'Wise L. Passive immune complex glomerulonephritis in mice: Models for various lesions found in human disease. II. Low avidity complexes and diffuse proliferative glomerulonephritis with subepithelial deposits. Lab Invest 1979; 41: 366

13. Koyama A, Inage $\mathbf{H}$, Kobayashi $\mathbf{M}$ et al. Role of antigenic charge and antibody avidity on the glomerular immune complex localization in serum sickness of mice. Clin Exp Immunol 1986; 64: 606

14. Border WA, Kamil ES, Ward HJ, Cohen AH. Antigenic charge as a determinant of immune complex localization in the rat glomerulus. Lab Invest 1981; 40: 442

15. Danon D, Goldstein L, Marikovsky Y, Skutelsky E. Use of cationized ferritin as a label of negative charges on cell surfaces. J Ultrastruct Res 1972; 38: 500

16. Hogendoorn PCW. De Heer E, Weening JJ. Daha MR, Hoedemaeker PhJ, Fleuren GJ. Glomerular capillary wall charge and antibody binding in passive Heymann nephritis. J Lab Clin Med 1988: 111: 150

17. Hogendoorn PCW, Bruijn JA, Van Den Broek LJCM el al. Antibodies to purified renal tubular epithelial antigens contain activity against laminin, fibronectin, and type IV collagen. $L a b$ Invest 1988; 58: 278

18. Daha MR, Van Es LA. Isolation. characterization and mechanism of action of rat B1H. J Immunol 1982; 128: 1839

19. Brentjens JR. O'Connell DW. Pawlowski IB, Andres GA. Extraglomerular lesions associated with deposition of circulating antigen-antibody complexes in kidneys of rabbits with chronic serum sickness. Clin Immunol Immunopathol 1974; 3: 112

20. Rennke HG, Venkatachalam MA. Structural determinants of glomerular permselectivity. Fed Proc 1977; 36: 2619

21. Rodenwald R, Karnowsky M. Porous substructure of the glomerular slit diaphragm in the rat and the mouse. / Cell Bio! 1974: 60: 423 
22. Salant DJ, Adler S, Darby C et ai. Influence of antigen distribution on the mediation of immunological glomerular injury. Kidney Int 1985; 27: 938

23. Fries JWU, Mendrick DL. Rennke HG. Determinants of immune complex-mediated glomerulonephritis. Kidney Int 1988; 34: 333

24. Sindrey M, Naish P. The mediation of the localization of po ly mo rp ho nuclear leucocytes in glomeruli during the autologous phase of nephrotoxic nephritis. Clin Exp Immunol 1979; 35: 350

25. Cochrane CG, Unanue ER, Dixon FJ. A role of polymorphonuclear leucocytes and complement in nephrotoxic nephritis. J Exp Med 1965; 122: 99

26. Schreiner GF, Cotran RS, Pardo V, Unanue ER. A mononuclear cell component in experimental immunological glomerulonephritis. J Exp Med 1978; 147: 369

27. Thaiss F, Batsford S, Mihatsch MJ, Heitz PU, Bitter-Suermann D, Vogt A. Mediator systems in a passive model of in situ immune complex glomerulonephritis. Role for complement, polymorphonuclear granulocytes and monocytes. Lab Invest 1986; 54: 624

28. Monga G, Mazzucco G, Barbiano di Belgioso G, Busnach G. The presence and possible role of monocyte infiltration in human. chronic proliferative glomerulonephritis. Am J Pathol 1979; 94: 271
29. Magil A, Wadsworth MB, Loewen M. Monocytes and human renal disease: a quantitative evaluation. Lab Invest 1981; 44: 27

30. Camussi G, Tetta C, Meroni M el al. Localization of cationic proteins derived from platelets and polymorphonuclear neutrophils and local loss of anionic sites in glomeruli of rabbits with experimentally induced acute serum sickness. Lab Invest 1986; 55: 56

31. Barnes JL, Venkatachalam MA, Enhancement of glomerular immune complex deposition by a circulating polycation. $J$ Exp Med 1984; 160: 286

32. Scbmiedeke TMI, Stöck] FW, Weber R, Sugisaki Y, Batsford SR, Vogt A. Histones have high affinity for the glomerular basement membrane. Relevance for immune complex formation in lupus nephritis. J Exp Med 1989; 169: 1879

33. Albini B, Brentjens JR, Andres GA. In: The Immunopathology of the Kidney. Current Topics in Immunology, Turk J, ed. London, Arnold, 1979

34. Noble B, Milgrom M, Van Liew JB, Brentjens JR. Chronic serum sickness in the rat: influence of antigen dose, route of antigen administration and strain of rat on the development of disease. Clin Exp Immunol 1987: 46: 499

35. Swaak AJG, Aarden LA, Statius Van Eps Y, Feltkamp TEW. Anti-ds DNA and complement profiles as prognostic guides in systemic lupus erythematosus. Arthritis Rheum 1979; 22: 226

36. Goldman M, Rose LM, Hochmann A, Lambert P-H. Deposition of idiotype-antiidiotype immune complexes in renal glomerul after polyclonal B-cell activation. J Exp Med 1982; 155: 1385

Receivedfor publication $\mathbf{1 . 6 . 9 2}$

Accepted in revisedform 5.1.93 